EGU2020-15270, updated on 24 Apr 2020

https://doi.org/10.5194/egusphere-egu2020-15270

EGU General Assembly 2020

(c) Author(s) 2020. This work is distributed under

the Creative Commons Attribution 4.0 License.

\title{
Remote Benthic Habitat Mapping Using Sunglint corrected multispectral Imagery in Bahrain waters
}

\author{
Manaf Alkhuzaei, Matthew Brolly, Niall Burnside, Chris Carey, and Georgios Maniatis \\ University of Brighton, School of Environment and Technology, United Kingdom of Great Britain and Northern Ireland \\ (m.alkhuzaei1@brighton.ac.uk)
}

The marine area of Bahrain comprises $91 \%$ of the total area of the country, the management of which is crucial for decision-makers, as it contains the country's most valuable resources. It is also ecologically important supporting such fauna as, sea dugong, dolphins, green turtles, and 70+ species of fish, and such flora as seagrass beds and algae which provide essential ecosystem services. Providing current benthic habitat maps using remote methods is vital for efficient management and monitoring of these dynamic resources. In this threefold study, remotely sensed Landsat 8/OLI and Sentinel-2 imagery, combined with field survey (176 points), are used to investigate, classify, and map benthic habitats in light of varying spatial and spectral image resolutions while also assessing the role sunglint correction methods perform. Two widely applied methodologies proposed by Hedley et al. (2005) and Lyzenga (2006) for sunglint correction in the water column are examined to assess their role in creating accurate classification maps in this region. Sunglint is an issue in Bahrain due to its shallow waters, long summer and clear skies. The results using unsupervised classification indicate the effectiveness of both correction methods, demonstrating comparable results of high classification accuracy using either 3 (Blue, Green and Red) or 4 (Coastal Aerosol, Blue, Green and Red) spectral band combinations. Maximum accuracy using Hedley was 74\% (4 bands) for Landsat 8 and $80 \%$ (3 bands) for Sentinel-2 while for Lyzenga $74 \%$ ( 4 bands) for Landsat 8 and $80 \%$ ( 3 bands) for Sentinel 2. The outputs generated were all $>68 \%$, with the introduction of more spectral bands associated with higher accuracy for Landsat 8 but inversely for Sentinel 2 . 